Original Article

\title{
Early Neurological Outcome of Surgical Repair of Lipomyelomeningocele in Infants
}

\author{
Shahid Iqbal, ${ }^{1}$ Lubna ljaz, ${ }^{1}$ Hassaan Zahid, ${ }^{1}$ Jamal Butt, ${ }^{1}$ Mariyum Iqbal ${ }^{2}$ \\ Malik Muhammad Nadeem ${ }^{1}$ \\ 'Department of Pediatric Neurosurgery, Children's Hospital and The Institute of Child Health, \\ ${ }^{2}$ Department of Cardiology, Punjab Institute of Cardiology, Lahore - Pakistan
}

\section{ABSTRACT}

Objective: A prospective cohort study was aimed to evaluate the early neurological outcome of surgery among infants having lipomyelomeningocele.

Material and Methods: The study was conducted at the Department of Pediatric neurosurgery, Children Hospital \&The Institute of Child Health, Lahore from January 2019 to June 2019.A total of 50 pediatric patients, both male and female, aged 3 months to 1 year, with lipomyelomeningocele (symptomatic or asymptomatic) who presented to the out-patient department were included in the study. Group A included those cases who were aged $<6$ months and Group B were aged $>6$ months. All patients underwent standard surgical procedures for the treatment of lipomyelomeningocele. Post-operative findings were recorded on the 3rd and 10th postoperative days for the immediate outcome while early outcomes were recorded at 6-months intervals.

Results: Out of a total of 50 infants, there was 32 (64.0\%) female. Overall, the mean age was $7.39 \pm 2.63$ months. The lumbar area having mass on the back was the most frequently seen in $23(46.0 \%)$ infants. Group A included 20 (40.0\%) infants while Group-B had 30 (60.0\%). Low lying cord was the commonest neurological finding noted among 25 (50.0\%). Complete Excision of Lipoma was done among 48 (96.0\%) infants. Postsurgery, no significant difference was found on day-3 and day-10 between study groups $(P>0.05)$. Early outcome at 6-months intervals was found to be associated with significantly improved neurological function grades in Group-A ( $p=0.030)$.

Conclusion: Surgical management of lipomyelomeningocele is a safe procedure. An early treatment approach even in asymptomatic infants is recommended to reduce neurological deterioration.

Keywords: Lipomyelomeningocele, Neurological Deterioration.

\section{Corresponding Author: Shahid Iqbal}

Department of Pediatric Neurosurgery

Children's Hospital and The Institute of Child Health

Lahore - Pakistan

Email: drshahid_202@hotmail.com
Date of Submission: 28-06-2021

Date of Revision: 30-07-2021

Date of Acceptance: 15-08-2021

Date of Online Publishing: 30-09-2021

Date of Print: 30-09-2021

DOI: $10.36552 /$ pjns.v25i3.584 


\section{INTRODUCTION}

Lipomyelomeningocele is a complex disorder of neural tube development. It may present with a wide range of neurological deficits due to inherent tethered cord. Management of lipomyelomeningocele is a difficult task for a pediatric neurosurgeon. ${ }^{1}$ There are two types of neural tube defects, open and closed types. Closed neural tube defects comprise lipomyelomeningocele, diastematomyelia, and spina bifida occulta. ${ }^{2}$ Lipomyelomeningocele is the most common closed neural tube defect. The reported incidence is 03 to 06 per 100,000 live birth. $^{2} \quad$ embryologically primary neurulation abnormalities including the process of disjunction (premature separation of neuralectoderm from epithelial ectoderm resulting in the fusion of the spinal cord with fatty elements. ${ }^{3}$

Pathogenesis of lipomyelomeningocele is different from other neural tube defects that's why not affected by the use of folic acid prophylactically. ${ }^{4-6}$ Presence of subcutaneous lipoma and its connection with cord limits upward growth of conus medullaris during child's axial growth, furthermore presence of a thickened filum terminale further restrictsthe movement due to its adherence with dura. Progressive fat deposition causing mass effect on cord and stretch lead to the decreased blood supply and increasing neurological deficit.

Hoffman et al. in a study found that $62.5 \%$ of patients were neurologically asymptomatic before 6 months of age whereas this decreased to $29 \%$ after 6 months of age. ${ }^{4}$ Appropriate treatments with complete resection of lipoma and untethering at an early age give good results whereas delay in treatment and incomplete excision of lipoma result in a neurological deficit. $^{7,8}$

Associated malformation with lipomyelomeningocele include genitourinary tract anomalies (4.1\%), split cord malformations(3.1\%), associated dermal sinuses (3.1\%), dermoid or epidermoid cysts (3.1\%), diastematomyelia (3.1\%), terminal hydromyelia (3.1\%), anal stenosis (1.0\%), and Down syndrome (1.0\%). ${ }^{4}$ Kanev et al. showed that $92 \%$ of the children with normal neurological examination preoperatively had no neurological deficit postoperatively while those children who had preoperative bowel and bladder incontinence did not improvemuch. ${ }^{9}$ Preoperative functions of the patients are directly related to surgical outcomes. ${ }^{10}$ Standard surgical procedures involve complete excision of lipoma, untethering of the cord, preservation of neural components, and prevention of retethering. ${ }^{11}$ In this study we planned to evaluate the early neurological outcome of surgery among both symptomatic and asymptomatic infants having lipomyelomeningocele.

\section{MATERIAL AND METHODS}

\section{Study Design and Setting}

This prospective cohort study was conducted in the department of Pediatric neurosurgery, Children Hospital \& The Institute of Child Health, Lahore from January 2019 to June 2019. Approval from Institutional Ethical Committee was taken. No conflict of interest was involved in the present research. Asymptomatic lipomyelomeningocele was labeled as children with lipomyelomeningocele without any neurological, orthopedic, urological deficit i.e. grade 0 of functional grading system devised by Hoffmann et al. ${ }^{4}$ Symptomatic lipomyelomeningocele was referred to as children with lipomyelomeningocele having any neurological, orthopedic, urological deficit i.e. grade 1 to 5 of functional grading system. ${ }^{4}$

\section{Inclusion Criteria}

A total of 50 consecutive patients of both genders, aged 3 months to 1 year having lipomyelomeningocele (symptomatic or 
asymptomatic) presenting in the out-patient department were enrolled.

\section{Exclusion Criteria}

All children who had any kind of surgery in the past, or having any ongoing current infections or patients with chronic medical illness were not included.

\section{Data Collection}

Medical history, clinical findings, and radiological investigations (e.g. MRI) were done in all patients. All patients were graded based on neurological and radiological assessment using functional grading scheme described by Hoffmann et al. ${ }^{4}$ Group A were those who were aged $<6$ months (both symptomatic and asymptomatic patients).and group B were aged > 6 months (both symptomatic and asymptomatic patients). All patients underwent standard surgical procedures for the treatment of lipomyelomeningocele. Post-operative findings were recorded on the 3rd and 10th postoperative days for the immediate outcome while the early outcome was recorded at 6-months intervals. Written consent was sought from parents/ guardians.

\section{Data Analysis Procedure}

Data was collected on a structured questionnaire specifically designed for this study. Data were analyzed using SPSS version 26.0. Age was represented as mean and standard deviation while frequencies and percentages were calculated for gender, area of residence, area of mass on back, neurological functional grades, neurological examination, clinical findings, and post-surgery complications/findings. The Chisquare test was applied considering $p$-value < 0.05 as significant.
RESULTS

\section{Demographics}

Out of a total of 50 infants, there were 18 (36.0\%) male and 32 (64.0\%) female. Overall, the mean age was $7.39 \pm 2.63$ months.

\section{Clinical Characteristics}

The majority of the infants, 29 (58.0\%) were symptomatic. The lumbar area having mass on the back was the most frequently seen in 23 (46.0\%) infants. Neurological examination functional grading revealed that there were 21 (42.0\%) with grade 0, 6 (12.0\%) grade 1, 10 (20.0\%) grade 2, 10 (20.0\%) grade 3 while 3 (6.0\%) were grade 4 . There were $20(40.0 \%)$ infants who were aged less than 6 months so they were slotted in Group-A while the remaining 30 (60.0\%) infants were aged above 6 months so were labeled as Group-B. Table 1 is showing a comparison of characteristics of infants among both study groups and a significant difference was observed ( $p>0.05)$.

\section{Neurological Examination Findings}

Table 2 is showing the frequency of the distribution of neurological examination among both study groups. Low lying cord was the most frequent neurological finding noted among 25 (50.0\%). No significant difference was noted between both study groups in terms of distribution of neurological examination $(p>0.05)$.

\section{Clinical Examination Findings}

Table 3 is showing a comparison of the frequency of various clinical examination findings between both study groups. Subcutaneous lipoma was the most common findings noted among 48 (96.0\%) infants. No statistically significant difference was noted between both study groups in terms of clinical examination findings. 
Table 1: Characteristics of Patients $(n=50)$.

\section{Characteristics}

Gender

Area of Residence

Symptoms

Area of Mass on Back

Area

Neurological Examination Functional Grades

$\begin{array}{lc}\text { Male } & \text { Group - A (n = 20) } \\ \text { Female } & 7(35.0 \%) \\ \text { Rural } & 13(65.0 \%) \\ \text { Urban } & 8(40.0 \%) \\ \text { Asymptomatic } & 12(60.0 \%) \\ \text { Symptomatic } & 10(50.0 \%) \\ \text { Sacral } & 10(50.0 \%) \\ \text { Transitional } & 10(50.0 \%) \\ \text { Lumbar } & 6(30.0 \%) \\ 0 & 4(20.0 \%) \\ 1 & 13(65.0 \%) \\ 2 & 2(10.0 \%) \\ 3 & 2(10.0 \%) \\ 4 & 3(15.0 \%) \\ & 0(0 \%)\end{array}$

$\begin{array}{cl}\text { Group - B (n = 30) } & \text { P-Value } \\ 11(36.7 \%) & 0.9043 \\ 19(73.3 \%) & \text { (insignificant) } \\ 14(46.7 \%) & 0.2468 \\ 16(53.3 \%) & \text { (insignificant) } \\ 11(36.7 \%) & 0.3494 \\ 19(73.3 \%) & \text { (insignificant) } \\ 5(16.7 \%) & 0.0073 \\ 6(20.0 \%) & \text { (insignificant) } \\ 19(73.3 \%) & \\ 8(26.7 \%) & \\ 4(13.3 \%) & 0.078 \\ 8(26.7 \%) & \text { (insignificant) } \\ 7(23.3 \%) & \\ 3(10.0 \%) & \end{array}$

Table 2: Distribution of Neurological Examination Findings $(n=50)$.

$\begin{array}{lrrrl}\text { Neurological Examination Findings } & \text { Total (\%) } & \begin{array}{c}\text { Group - A } \\ (\mathbf{n = 2 0 )}\end{array} & \begin{array}{c}\text { Group - B } \\ \mathbf{( n = 3 0 )}\end{array} & \text { P-Value } \\ \text { Vertebral anomalies } & 5(10.0 \%) & 1(5.0 \%) & 4(13.3 \%) & 0.3359 \text { (insignificant) } \\ \text { Low lying cord } & 25(50.0 \%) & 12(60.0 \%) & 20(66.7 \%) & 0.6304 \text { (insignificant) } \\ \text { Diastematomyelia } & 10(20.0 \%) & 3(15.0 \%) & 7(23.3 \%) & 0.4705 \text { (insignificant) } \\ \text { Syrinx } & 10(20.0 \%) & 3(15.0 \%) & 7(23.3 \%) & 0.4705 \text { (insignificant) } \\ \text { Ultrasonography kidney, ureter and } & 30(60.0 \%) & 12(60.0 \%) & 18(60.0 \%) & 1 \text { (insignificant) } \\ \text { bladder normal } & 15(30.0 \%) & 6(30.0 \%) & 9(30.0 \%) & 1 \text { (insignificant) } \\ \begin{array}{l}\text { Dilated urinary bladder } \\ \text { Neurogenic bladder with hydroureter } \\ \text { and hydrocephalus }\end{array} & 5(10.0 \%) & 2(10.0 \%) & 3(10.0 \%) & 1 \text { (insignificant) }\end{array}$

Table 3: Distribution of Frequency of Clinical Examination Findings $(n=50)$.

\begin{tabular}{lcccl} 
Clinical Examination Findings & Total (\%) & Group - A (n = 20) & Group - B (n= 30) & P-Value \\
Subcutaneous Lipoma & $48(96.0 \%)$ & $18(90.0 \%)$ & $30(100.0 \%)$ & 0.0771 (insignificant) \\
Tail Like Appendages & $9(18.0 \%)$ & $4(20.0 \%)$ & $5(16.7 \%)$ & 0.7638 (insignificant) \\
Asymptomatic Gluteal Folds & $11(22.0 \%)$ & $4(20.0 \%)$ & $7(23.3 \%)$ & 0.7804 (insignificant) \\
Hemangioma (subcutaneous) & $7(14.0 \%)$ & $2(10.0 \%)$ & $5(16.7 \%)$ & 0.5057 (insignificant) \\
Scar Like Skin Patches & $3(6.0 \%)$ & $0(0 \%)$ & $3(10.0 \%)$ & 0.1450 (insignificant) \\
Skin Dimples & $9(18.0 \%)$ & $2(10.0 \%)$ & $7(23.3 \%)$ & 0.2293 (insignificant) \\
\hline
\end{tabular}

\section{Post-Operative Findings}

Complete Excision of Lipoma was done among 48 (96.0\%) infants while incomplete excision of Lipoma was done in the remaining 2 (4.0\%). Filum Terminale was identified among 32 (64.0\%) infants. Table 4 is showing a comparison of postoperative complications/findings among both study groups. Table 5 shows that postsurgery, no significant difference was found at da3 and day-10 between study groups ( $P>0.05)$. CSD Leakage from the wound was noted in 1 infant in Group - A versus 2 in Group - B ( $p=$ 0.8079 ) and all these 3 cases were re-operated. One patient in Group - A as Grade 1 with right 
Table 4: Post-Operative Complications/Findings.

\begin{tabular}{|c|c|c|c|c|c|}
\hline Period & $\begin{array}{l}\text { Post-Operative } \\
\text { Complications/Findings }\end{array}$ & & $\begin{array}{c}\text { Group - A } \\
(n=20)\end{array}$ & $\begin{array}{c}\text { Group - B } \\
(n=30)\end{array}$ & $P$ value \\
\hline \multirow{2}{*}{ Day-3 } & Surgical Site Infection & & 0 & 0 & 1 (insignificant) \\
\hline & Seroma & & 5 & 4 & 0.2928 (insignificant) \\
\hline \multirow{2}{*}{ Day-10 } & Surgical Site Infection & & 4 & 6 & 1 (insignificant) \\
\hline & Seroma & & 5 & 4 & 0.2928 (insignificant) \\
\hline \multirow{5}{*}{ At 6-months } & & 0 & 15 & 10 & \\
\hline & & 1 & 0 & 5 & \\
\hline & Neurological Function Grades & 2 & 2 & 5 & 0.030 (significant) \\
\hline & & 3 & 3 & 6 & \\
\hline & & 4 & 0 & 4 & \\
\hline
\end{tabular}

congenital talipes equinovarus (CTEV) had ponseti casting but no improvement was observed postoperatively so that case was later on planned to undergo a posteromedial-release (PMR). Early outcome at 6-months interval was found to be associated with significantly improved neurological function grades as 15 (75.0\%) infants in Group-A had Grade-4 function grades whereas all 4 cases of Grade-4 were found to be in Group$B(p=0.030)$. No deaths were reported.

\section{DISCUSSION}

Lipomeningomyelocele is rare condition affection affecting 3-6 per 100000 livebirths. $^{2}$ Variation in presentation and underlying pathology influence clinical approaches towards treating lipomyelomeningocele. In the present study, it was noted that $65.0 \%$ of infants in Group - A were having Grade - 0 neurological functional grades in comparison to $26.7 \%$ in Group - B so it was seen that children aged below 6 months were having less deteriorated neurological functional grades. Group - B was noted to have $10 \%$ infants with Grade - 4 neurological functional grades in comparison to no infant in Group - A. It has been observed in the past that lipomeningomyeloceleis commonly found to be linked with cutaneous as well as musculoskeletal dysfunction while sensorimotor and urological abnormalities are also observed frequently. ${ }^{12} \quad$ Neurological manifestations are often not present in about
$50 \%$ of the cases at the time of birth while as infants grow, progression in loss of neurological functioning might be visible. ${ }^{7}$ With axial growth, lower limb and sacral motor and sensory abnormalities manifest among infants with lipomeningomyelocele. ${ }^{4}$ We noted that a low lying cord was the most frequent neurological finding noted among $50.0 \%$ of infants in the present study. A study from Nepal reported as many as $92.3 \%$ of their cases to have a low-lying cord. ${ }^{13}$

In the present study, complete excision of lipoma was done among $96.0 \%$ of infants. Surgery is considered to be the mainstay of lipomeningomyelocele treatment. The role of surgery before manifestations of neurological symptoms surrounds controversies. ${ }^{14,15}$ Kuklerni and colleagues quoted a $33 \%$ chance of deterioration of symptoms among those cases that were managed conservatively in comparison to $46 \%$ in surgically treated cases. ${ }^{16}$ Researchers have pointed out that surgical outcomes of lipomyelomeningocele closely correlate with the pre-surgery functioning of the cases. ${ }^{17}$

In the present study, we found that no significant difference was noted in terms of neurological functional grades at baseline between both study cases but the outcome at 6 months interval was found to be associated with significantly improved neurological function in infants aged less than 6 months at the time of 
surgery $(p=0.030)$. Pang et al endorsed an aggressive approach to treating lipomyelomeningocele and advised complete resection of lipoma. They noted $88.1 \%$ of the cases to have no neurological deterioration at 20year follow up in comparison to $35 \%$ chances of progression at 10 - year follow up among cases with partial resection of lipoma. ${ }^{18}$ Very similar to the present study, a study from Nepal recommended that patients should be counseled and encouraged to go for the early repair of lipomyelomeningocele as cases with established neurological insult are noted to have less improved outcomes in comparison to those treated early and with less severe neurological functional grades. ${ }^{13}$ A study from China pointed towards the early treatment of lipomyelomeningocele even if patients are asymptomatic as it can prevent progression of neurological abnormalities. ${ }^{19}$

\section{CONCLUSION \& RECOMMENDATIONS}

Surgical management of lipomyelomeningocele is a safe procedure. An early treatment approach even in asymptomatic infants is recommended to reduce neurological deterioration. Our study had some limitations as well. As this was a singlecenter study with relatively small sample size, the findings of this study cannot be generalized. We had observed comparatively short-term outcomes of infants undergoing lipomyelomeningocele repair so more studies exploring long-term outcomes and follow-ups should be planned to watch out for the long-term complications and outcomes.

\section{REFERENCES}

1. Arai $H$, Sato $K$, Okuda $O$, Miyajima $M$, Hishii $M$, Nakanishi $H$, et al. Surgical experience of 120 patients with lumbosacral lipomas. Acta Neurochir (Wien). 2001; 143: 857-64.

2. Forrester MB, Merz RD. Descriptive epidemiology of lipomyelomeningocele, Hawaii, 1986-2001. Birth
Defects Research Part A: Clinical and Molecular Teratology, 2004; 70 (12): 953-6.

3. Warder DE. Tethered cord syndrome and occult spinal dysraphism. Neurosurg Focus, 2001; 10: e1.

4. Hoffman HJ, Taecholarn C, Hendrick EB, Humphreys RP. Management of lipomyelomeningoceles. Experience at the hospital for sick children, Toronto. J Neurosurg. 1985; 62: 1-8.

5. Frey L, Hauser WA. Epidemiology of neural tube defects. Epilepsia, 2003; 44 (Suppl. 3): 4-13.

6. McNeely PD, Howes WJ. Ineffectiveness of dietary folic acid supplementation on the incidence of lipomyelomeningocele: Pathogenetic implications. J Neurosurg. 2004; 100 (2 Suppl): 98-100.

7. Hertzler DA, 2nd, DePowell JJ, Stevenson CB, Mangano FT. Tethered cord syndrome: A review of the literature from embryology to adult presentation. Neurosurg Focus, 2010; 29: e1.

8. Huang SL, Shi W, Zhang LG. Surgical treatment for lipomyelomeningocele in children. World J Pediatr. 2010; 6: 361-5.

9. Kanev PM, Lemire RJ, Loeser JD, Berger MS. Management and long-termfollow-up review of childrenwith lipomyelomeningocele, 19521987. J Neurosurg. 1990; 73: 48-52.

10. Hashim ASM, Ahmed S, Jooma R. Management of myelocele. J Surg Pakistan (International), 2008; 13 (1): 7-11.

11. Patil PS, Abhaya Gupta. Immediate and long term outcome analysis of lipomeningomyelocele repair in asymptomatic infants in a tertiary care center. J Pediatr Neurosci. 2016; 11 (2): 99-104 Doi: $10.4103 / 18171745.187619$

12. Muthukumar N. Congenital spinal lipomatos malformations: Part I - Classification. Acta Neurochir. 2009; 151: 179-88.

13. Koirala PR, Pradhanang AB, Sedain G, Sharma MR. Outcome Analysis of Lipomeningomyelocele Repair in Children in a Tertiary Care Center in Nepal. JOIM Nepal, 2019; 41 (2): 30-34.

14. Wagner KM, Raskin JS, Hansen D, Reddy GD, Jea A, Lam S. Surgical management of lipomyelomeningocele in children: Challenges and considerations. Surg Neurol Int. 2017; 8: 63. doi:10.4103/2152-7806.205268

15. Yerkes EB, Halline C, Yoshiba G, Meyer TA, Rosoklija I, Bowman $\mathrm{R}$, et al. 
Lipomyelomeningocele for the urologist: Should we view it the same as myelomeningocele? J Pediatr Urol. 2017; 13 (4): 371.e1-371.e8.

Doi: 10.1016/j.jpurol.2017.04.014

16. Kulkarni AV, Pierre-Kahn A, Zerah M. Conservative management of asymptomatic spinal lipomas of the conus. Neurosurgery, 2004; 54: 868-73.

17. Pierre-Kahn A, Lacombe J, Pichon J, et al. Intraspinal lipomas with spina bifida. Prognosis and treatment in 73 cases. J Neurosurg. 1986; 65: 756-61.

18. Pang D, Zovickian J, Wong ST, et al. Surgical treatment of complex spinal cord lipomas. Childs Nerv Syst. 2013; 29: 1485-13.

19. Huang SL, Shi W, Zhang LG. Surgical methods and techniques of lipomyelomeningocele in children. Zhonghua WaiKe ZaZhi. 2010; 48 (10): 750-2.

\section{Additional Information}

Disclosures: Authors report no conflict of interest.

Ethical Review Board Approval: The study was conformed to the ethical review board requirements.

Human Subjects: Consent was obtained by all patients/participants in this study.

\section{Conflicts of Interest:}

In compliance with the ICMJE uniform disclosure form, all authors declare the following:

Financial Relationships: All authors have declared that they have no financial relationships at present or within the previous three years with any organizations that might have an interest in the submitted work.

Other Relationships: All authors have declared that there are no other relationships or activities that could appear to have influenced the submitted work.

\section{AUTHORS CONTRIBUTIONS}

\begin{tabular}{|l|l|l|}
\hline Sr.\# & Author's Full Name & Intellectual Contribution to Paper in Terms of: \\
\hline 1. & Shahid lqbal & Study design and methodology \\
\hline 2. & Lubna ljaz & Paper writing and data calculations \\
\hline 3. & Hassaan Zahid & Data collection and calculations \\
\hline 4. & Jamal Butt & Analysis of data and interpretation of results etc. \\
\hline 5. & Mariyum lqbal & Literature review and referencing \\
\hline 6. & Malik Muhammad Nadeem & Analysis of data and quality insurer \\
\hline
\end{tabular}

